\title{
EU research activities in alternative testing strategies: current status and future perspectives
}

\author{
T. Vanhaecke $\cdot$ S. Snykers $\cdot$ V. Rogiers $\cdot$ B. Garthoff \\ J. V. Castell $\cdot$ J. G. Hengstler
}

Published online: 12 November 2009

(C) Springer-Verlag 2009

\section{Current EU research initiatives}

Alternative testing methods have become increasingly important within EU funding policy. The driving force behind this push for alternative testing methods is the urgent need for effective and robust alternative toxicity tests in order to make the tools available that are necessary to comply with the 3R-strategy (Replacement, Reduction, Refinement) that has been built into the European Cosmetic (Directive 2003/15/EC) and Chemical (REACH)

T. Vanhaecke $(\varangle) \cdot$ S. Snykers $\cdot$ V. Rogiers

Department of Toxicology, Vrije Universiteit Brussel,

Laarbeeklaan 103, 1090 Brussels, Belgium

e-mail: tamara.vanhaecke@vub.ac.be

S. Snykers

e-mail: sarah.snykers@vub.ac.be

V. Rogiers

e-mail: vrogiers@vub.ac.be

B. Garthoff

Bayer AG DE, Kaiser-Wilhelm-Allee,

W11, 51368 Leverkusen, Germany

e-mail: bernward.garthoff@bayercropscience.com

J. V. Castell

Departmento de Bioquimica Facultad de Medicina, Centro de Investigacion, Hospital Universitario La Fe,

Avenida de Campanar 21, 46009 Valencia, Spain

e-mail: jose.castell@uv.es

J. G. Hengstler

Leibniz-Institut für Arbeitsforschung an der TU Dortmund,

Leibniz Research Centre for Working Environment

and Human Factors (IfADo), Ardeystrasse 67,

44139 Dortmund, Germany

e-mail: hengstler@ifado.de
(Regulation EC No 1907/2006) legislations. Indeed, a general European policy has to take into consideration the growing ethical concern of the public with respect to the use of experimental animals in the risk assessment process of consumer products. It is reasonable to believe that further development and strategic incorporation of recent progress in different areas of scientific research could lead to a better and more mechanistically based approach of studying toxicological problems. In line with this, the pharmaceutical industry is confronted with unexpected failures during the drug development process, even late during the clinical phase. These could not be properly anticipated. Reasons are in particular safety (hepato- and cardiotoxicity) as well clinical efficacy of the new chemical entities. Therefore, incorporation of novel alternative methods, human based and metabolically functional, is high on the priority list since the competitiveness of the European pharmaceutical industry is at stake.

An overview of the different EU initiatives in the context of the 3Rs funded research is given in EUR22846 (European Commission 2008) and in the update EUR23886 (European Commission 2009). The EU offers four different funding schemes: (1) Collaborative/Integrated projects, which are medium/large-sized ambitious projects, usually involving several areas of expertise, (2) Specific Targeted Research Projects (STREP), representing smaller networks focussed on specific research issues, (3) SME-STREP, aimed at supporting research of small- and medium-sized enterprises (SMEs), and (4) Specific Support Actions (SSA), for scientific training of personal as well as organization of conferences, workshops and expert meetings (EUR22846, EUR23886). The research networks fall into the categories of high-throughput techniques, specific toxicity tests and organization of forums and workshops. 


\section{Limitations of "one-to-one" strategies}

A substantial part of current research focuses on "one-toone" strategies aimed at replacing a particular in vivo test by a specific alternative technique. This is currently the case both in regulatory toxicology as well as in efficacy testing of substances. In regulatory toxicology, the risk assessment process of chemical substances and hazard identification are usually carried out using experimental animals. A typical example of a replacement methodology is Episkin ${ }^{\circledR}$ aimed at replacing in vivo skin irritation assays (EU 2009a B.46; OECD 2009a). The up-and-down method can reduce the number of animals used in acute toxicity testing (OECD 2001; OECD 2009b), and a refinement test is the LLNA test (Local Lymph Node Assay) (EU 2009b B.42; OECD 2002) for sensitisation testing. Examples can also be provided for efficacy testing of new chemical entities that rely solely on animal experiments. Alternatives currently used and presently investigated include the robotised enzyme testing aimed at identifying candidates acting at different stages on a specific enzymatic pathway, or ligand-based assays (such as e.g. radioimmunoassays in the past) developed for assessing effects on a particular target. Unfortunately, despite the efforts of numerous individuals, including many highly respected researchers, and the investment of millions of euros by the European Commission, various industries, and private institutions, no real breakthrough has been accomplished yet. Indeed, although the "one-toone" replacement strategy has contributed towards the development of the alternative strategies used today and/ or taken up in the EU regulatory framework, full implementation of 3R-alternatives has not been achieved. The in vivo scenario is thus significantly more complex than envisaged, and substitution by the "one-to-one" in vitro strategy seems unrealistic. Therefore, it is of utmost importance to bring innovative ideas to the field of the 3Rs and not limit experimental strategies to simple test systems and endpoints that are unable to provide a scientifically satisfactory answer to the complex in vivo reality. Hence, more consideration should be given to the complexity of the organism, which allows for the better integration of the information generated into a more solid decision-making strategy.

\section{Integration of new crosscutting technologies}

Important areas for deeper exploitation in alternative testing research correspond to the topics that were identified by top scientists during the meeting on "New Perspectives on Safety" organized by epaa (European Partnership for Alternative Approaches to Animal Testing) in April 2008 (epaa Workshop Report 2008). These key technologies are as follows.

\section{Toxicogenomics}

Progress in this field has been achieved by the identification of algorithms that allow classification of toxic mechanisms from gene expression data. Examples of such mechanisms include oxidative stress response, DNA damage response, and responses mediated by activation of specific receptors. One of the limitations of this approach is that toxic mechanisms can be identified only qualitatively. Currently, no clear concept is available on how quantitative information on in vivo dose-response relationships and identification of NOELs (no observable effect levels) are to be obtained. Perhaps, a combination of toxicogenomics with kinetic modelling may be a perspective and will help guide in vitro testing at in vivo relevant concentrations (Thum and Borlak 2008; Glahn et al. 2008; Degen and Hengstler 2008; Dewa et al. 2007; Sul et al. 2007; Schug et al. 2008; Ryan et al. 2008; Sistare and Degeorge 2008; Ellinger-Ziegelbauer et al. 2009).

\section{Metabonomics}

The major advantage of using technologies that screen across many different cellular metabolic parameters is their ability to produce metabolic fingerprints of toxicants. Because changes in these metabolites are thought to precede toxic outcomes, appropriate changes may serve as early, sensitive indicators of potential toxicity and can then be used to help guide decision making with regard to compound classification. An important issue that remains unsolved is how to integrate metabonomics into testing strategies. Compared with transcriptomics, metabonomic approaches have been less frequently used in predictive toxicology. Yet there are indications that by using global profiling tools, the predictive value of the metabonomics data should greatly increase (Nicholson and Lindon 2008; Pelkonen et al. 2008; Strassburg et al. 2008; Robertson et al. 2007; Vangala and Tonelli 2007; Lahoz et al. 2007).

\section{Systems biology}

As mentioned earlier, more consideration should be given to the complexity of the organism. Systems biology could provide some suitable answers as it is concerned with a global multivariate strategy to cover the full understanding of the cellular responses during the transition from physiology to pathology. Therefore, predictive models need to be developed based on the identification, analysis, and modelling of pathways involved in these processes. These models should combine high-throughput, systematic 
analysis techniques in genetics, epigenetics, transcriptomics, proteomics and/or metabolomics with relevant areas of informatics/modelling (Naamane et al. 2007; Höhme et al. 2007; Klingmüller et al. 2006; Schrattenholz and Soskić 2008; Krewski et al. 2009).

\section{Stem cells}

While recent research shows that stem cells have the potential to differentiate into any cell type, therefore, providing an unlimited supply of differentiated human cells for in vitro testing, such goal has not been achieved yet. The lack in success is in part due to the difficulty of having fully differentiated and functionally equivalents to primary cells (Hewitt et al. 2007) indicating a need for further research to help identify new technologies. Actually, embryonal as well as adult stem cells are both used and can be differentiated into functional human target cells of importance in toxicology. Basic research, however, remains necessary to understand the different parameters defining the exposure (time, type, sequence) to individual key growth factors and cytokines and potential combinations to achieve the appropriate phenotype (Snykers et al. 2007a; Elaut et al. 2006; Brulport et al. 2007; Hengstler et al. 2005; Aurich et al. 2007; Bonora-Centelles et al. 2008).

\section{Epigenetics}

It is known that epigenetic modification of the nucleosomal chromatin in primary cells and cell lines have great effects on the differentiation/proliferation status of the cells under consideration. The best investigated mechanisms in this respect are histone deacetylation-acetylation and DNA methylation-demethylation. Both processes could play an important role in functional stabilization of primary cells as well as in the ultimate differentiation of stem cells into functional human cells. The latter is of importance not only in toxicological processes, but also in the study of the efficacy of new chemical entities. Future research trends should focus on the impact of epigenetic modifiers on the phenotype, with special emphasis on the role of micro RNAs, as a regulatory platform driving gene expression (Henkens et al. 2007; Vinken et al. 2006; Snykers et al. 2007b; Eilertsen et al. 2008; Lunyak and Rosenfeld 2008; Gan et al. 2007; Datta et al. 2008; Costa 2008; Egger et al. 2004; Carthew and Sontheimer 2009).

\section{Integrated testing strategies}

One of the most important challenges when attempting to replace animal experiments is to integrate individual alternative techniques into a reasonable overall testing strategy. Ideas to develop such strategies, however, are not available yet. This requires discussion between academia scientists, active in the development of alternative methods, and industry staff involved in the decision-making process during the development of new chemical entities. Besides essential networking and collaboration between all parties involved, a number of available methodologies need updating and a better definition of their applicability domain. The lack of xenobiotic metabolizing activity in most of the existing alternative methods has not been properly solved and needs to be urgently addressed (Lilienblum et al. 2008; Bolt and Hengstler 2008a, b; Bolt et al. 2004).

\section{Modelling}

Although systems biology can be seen as a "modelling" technology, other important fields in "modelling" need to be pursued as well, such as (Q)SAR ((Quantitative) Structure Activity Relationships) and PBPK (Physiologically based Pharmacokinetic) modelling with more importance given to the improvement of biokinetics in order to better guide in vitro testing at using concentrations that are relevant to the in vivo situation. Also, further improvement and development of databases and software are needed in order to facilitate integration (Jaworska and Nikolova-Jeliazkova 2007; Dorn et al. 2008; Lu et al. 2008).

\section{Lack of an independent data trader institution}

It has been insistently demanded by experts in alternative testing that existing data- on a worldwide basis—should be available in order to avoid unnecessary animal testing in safety and efficacy testing of compounds. However, no reality proof proposal has been elaborated and put forward. Best example for this is the lack of an independent, unbiased, worldwide institution which in particular supports stakeholder parties, by providing unbiased assistance and advice, or even better, by serving as an independent data broker. An institution like this was early on demanded in the academic and industrial scene (Todd et al. 1998) by alternative methods research scientists and other stakeholders. The rationale for such an institution is to exchange data of in vivo, in vitro testing for e.g. validation studies, which otherwise cannot be used because of being IP- or submission-regulated data.

There have been a few examples where (Gerbracht and Spielmann 2001; Box and Spielmann 2005) appropriately codified data were made available for comparison evaluations, thanks to the intervention of a neutral institution. In this sense, "appropriately codified" data coming from e.g. industrial companies could be handled and used by academics in their research on a worldwide basis. This will 
address the often uttered need for exchange of relevant data (also emphasized at the epaa Workshop in Brussels, Nov. 3,2008 ) by developing an appropriate blueprint for such an agency or institution. An independent and neutral institution like this is also highly necessary to allow waiving of data as described as a tool within REACH legislation (annex 11) (Regulation EC No 1907/2006) to reduce animal testing. If such institution is not created, data exchange will not be possible. ECHA (European Chemicals Agency) is not allowed to provide data to others, and industries too may not do it because of anti-trust legislation.

In conclusion, until recently, EU research initiatives have been aimed at developing specific alternatives that could replace existing in vivo methods one by one. Time has come now to abandon these procedures and to pursue a more advanced strategy by putting more emphasis into the complexity of the organism as a whole. A first onset of such thinking has been given by the commission with the coordination project "START-UP", aimed at identifying bottlenecks in the use of 3R-alternatives in pharmaceutical development. We feel that a much more cooperative approach crosscutting academia, institutions, and industries has to be developed. Therefore, an important step forward could be a research-driven follow-up of the cluster of calls recently launched by DG Research and Colipa (The European Cosmetics Association) (FP7-Health-2010Alternative-Testing) with respect to repeated dose toxicity testing, aiming to address in an integrated approach all themes mentioned earlier.

\section{References}

Aurich I, Mueller LP, Aurich H, Luetzkendorf J, Tisljar K, Dollinger MM, Schormann W, Walldorf J, Hengstler JG, Fleig WE, Christ B (2007) Functional integration of hepatocytes derived from human mesenchymal stem cells into mouse livers. Gut 56(3): $405-415$

Bolt HM, Hengstler JG (2008a) Most cited articles in the archives of toxicology: the debate about possibilities and limitations of in vitro toxicity tests and replacement of in vivo studies. Arch Toxicol 82(12):881-883

Bolt HM, Hengstler JG (2008b) The past and the future of toxicology. Arch Toxicol 82(1):1-3

Bolt HM, Foth H, Hengstler JG, Degen GH (2004) Carcinogenicity categorization of chemicals-new aspects to be considered in a European perspective. Toxicol Lett 151(1):29-41

Bonora-Centelles A, Castell JV, Gómez-Lechón MJ (2008) Adipose tissue-derived stem cells: hepatic plasticity. Gastroenterol Hepatol 31(5):299-309

Box RJ, Spielmann H (2005) Use of the dog as non-rodent test species in the safety testing schedule associated with the registration of crop and plant protection products (pesticides): present status. Arch Toxicol 79:615-626

Brulport M, Schormann W, Bauer A, Hermes M, Elsner C, Hammersen FJ, Beerheide W, Spitkovsky D, Härtig W, Nussler A, Horn LC, Edelmann J, Pelz-Ackermann O, Petersen J,
Kamprad M, von Mach M, Lupp A, Zulewski H, Hengstler JG (2007) Fate of extrahepatic human stem and precursor cells after transplantation into mouse livers. Hepatology 46(3):861-870

Carthew RW, Sontheimer EJ (2009) Origins and mechanisms of miRNAs and siRNAs. Cell 136(4):642-655

Costa FF (2008) Non-coding RNAs, epigenetics and complexity. Gene 410:9-17

Datta J, Kutay H, Nasser MW, Nuovo GJ, Wang B, Majumder S, Liu CG, Volinia S, Croce CM, Schmittgen TD, Ghoshal K, Jacob ST (2008) Methylation mediated silencing of MicroRNA-1 gene and its role in hepatocellular carcinogenesis. Cancer Res 68:5049 5058

Degen GH, Hengstler JG (2008) Developments in industrial and occupational toxicology: REACH, toxicogenomics, mycotoxins, lead, asbestos, boron, bitumen, deletions polymorphisms and SNP interactions: meeting report of the 16th EUROTOX training and discussion session. Arch Toxicol 82(7):483-487

Dewa Y, Nishimura J, Muguruma M, Matsumoto S, Takahashi M, Jin M, Mitsumori K (2007) Gene expression analyses of the liver in rats treated with oxfendazole. Arch Toxicol 81(9):647-654

Directive 2003/15/EC of the European parliament and of the council of 27 February 2003 amending council directive 76/768/EEC on the approximation of the laws of the member states relating to cosmetic products. Official Journal L066, 26-35, 11 March 2003

Dorn SB, Degen GH, Bolt HM, van der Louw J, van Acker FA, van den Dobbelsteen DJ, Lommerse JP (2008) Some molecular descriptors for non-specific chromosomal genotoxicity based on hydrophobic interactions. Arch Toxicol 82(5):333-338

Egger G, Liang G, Aparicio A, Jones PA (2004) Epigenetics in human disease and prospects for epigenetic therapy. Nature 429:457463

Eilertsen KJ, Floyd Z, Gimble JM (2008) The epigenetics of adult (somatic) stem cells. Crit Rev Eukaryot Gene Expr 18(3):189206

Elaut G, Henkens T, Papeleu P, Snykers S, Vinken M, Vanhaecke T, Rogiers V (2006) Molecular mechanisms underlying the dedifferentiation process of isolated hepatocytes and their cultures. Curr Drug Metab 7(6):629-660

Ellinger-Ziegelbauer H, Aubrecht J, Kleinjans JC, Ahr HJ (2009) Application of toxicogenomics to study mechanisms of genotoxicity and carcinogenicity. Toxicol Lett 186(1):36-44

epaa (2008) Workshop report on new perspectives on safety, Brussels, pp 28-29

EU (2009a) B.46. In vitro skin irritation: Reconstructed Human Epidermis Model Test. Commission Regulation (EC) No761/ 2009 of 23 July 2009 amending, for the purpose of its adaptation to technical progress, Regulation (EC) No 440/2008 laying down test methods pursuant to regulation (EC) No 1907/2006 of the European parliament and of the council on the registration, evaluation, authorisation and restriction of chemicals (REACH) Official Journal L220, 24/08/2009, 24-31

EU (2009b) B.42. Skin sensitisation: local lymph node assay. Commission regulation (EC) No 761/2009 of 23 July 2009 amending, for the purpose of its adaptation to technical progress, Regulation (EC) No 440/2008 laying down test methods pursuant to Regulation (EC) No 1907/2006 of the European Parliament and of the Council on the Registration, Evaluation, Authorisation and Restriction of Chemicals (REACH) Official Journal L220, 24/08/2009, 414-419

EUR22846 (2008) Project synopses of EU-supported research 20022006 on alternative testing strategies. Replacing, reducing and refining use of animals in research. European commission directorate f-health unit 5 health biotechnology (contact $\mathrm{J}$. Beusing). In: Kessler C (ed) 2008

EUR23886 (2009) Progress report on alternative testing strategies. Replacing, reducing and refining use of animals in research. 
European commission directorate F-health unit 5 health biotechnology (contact J. Beusing). In: Nogueiro M (ed) 2009

FP7-Health-2010-Alternative-Testing; http://cordis.europa.eu/fp7/dc/ index.cfm?fuseaction=UserSite.CooperationDetailsCallPage\&call_ id=280; consultation date 29/09/2009

Gan Q, Yoshida T, McDonald OG, Owens GK (2007) Concise review: epigenetic mechanisms contribute to pluripotency and cell lineage determination of embryonic stem cells. Stem Cells 25(1):2-9

Gerbracht U, Spielmann H (2001) The use of dogs as second species in regulatory testing of pesticides. Part II: subacute, subchronic and chronic studies in the dog. Arch Toxicol 75:1-21

Glahn F, Schmidt-Heck W, Zellmer S, Guthke R, Wiese J, Golka K, Hergenröder R, Degen GH, Lehmann T, Hermes M, Schormann W, Brulport M, Bauer A, Bedawy E, Gebhardt R, Hengstler JG, Foth H (2008) Cadmium, cobalt and lead cause stress response, cell cycle deregulation and increased steroid as well as xenobiotic metabolism in primary normal human bronchial epithelial cells which is coordinated by at least nine transcription factors. Arch Toxicol 82(8):513-524

Hengstler JG, Brulport M, Schormann W, Bauer A, Hermes M, Nussler AK, Fandrich F, Ruhnke M, Ungefroren H, Griffin L, Bockamp E, Oesch F, von Mach MA (2005) Generation of human hepatocytes by stem cell technology: definition of the hepatocyte. Expert Opin Drug Metab Toxicol 1(1):61-74

Henkens T, Papeleu P, Elaut G, Vinken M, Rogiers V, Vanhaecke T (2007) Trichostatin A, a critical factor in maintaining the functional differentiation of primary cultures rat hepatocytes. Toxicol Appl Pharmacol 218:64-71

Hewitt ZA, Amps KJ, Moore HD (2007) Derivation of GMP raw materials for use in regenerative medicine: hESC-based therapies, progress toward clinical application. Clin Pharmacol Ther 82(4):448-452

Höhme S, Hengstler JG, Brulport M, Schäfer M, Bauer A, Gebhardt R, Drasdo D (2007) Mathematical modelling of liver regeneration after intoxication with $\mathrm{CCl}(4)$. Chem Biol Interact 168(1):74-93

Jaworska J, Nikolova-Jeliazkova N (2007) How can structural similarity analysis help in category formation? SAR QSAR Environ Res 18(3-4): 195-207

Klingmüller U, Bauer A, Bohl S, Nickel PJ, Breitkopf K, Dooley S, Zellmer S, Kern C, Merfort I, Sparna T, Donauer J, Walz G, Geyer M, Kreutz C, Hermes M, Götschel F, Hecht A, Walter D, Egger L, Neubert K, Borner C, Brulport M, Schormann W, Sauer C, Baumann F, Preiss R, MacNelly S, Godoy P, Wiercinska E, Ciuclan L, Edelmann J, Zeilinger K, Heinrich M, Zanger UM, Gebhardt R, Maiwald T, Heinrich R, Timmer J, von Weizsäcker F, Hengstler JG (2006) Primary mouse hepatocytes for systems biology approaches: a standardized in vitro system for modelling of signal transduction pathways. Syst Biol (Stevenage) 153(6):433-447

Krewski D, Andersen ME, Mantus E, Zeise L (2009) Toxicity testing in the 21st century: implications for human health risk assessment. Risk Anal 29(4):474-479

Lahoz A, Donato MT, Picazo L, Gómez-Lechón MJ, Castell JV (2007) Determination of major human cytochrome P450 s activities in 96-well plates using liquid chromatography tandem mass spectrometry. Toxicol In Vitro 21(7):1247-1252

Lilienblum W, Dekant W, Foth H, Gebel T, Hengstler JG, Kahl R, Kramer PJ, Schweinfurth H, Wollin KM (2008) Alternative methods to safety studies in experimental animals: role in the risk assessment of chemicals under the new European chemicals legislation (REACH). Arch Toxicol 82(4):211-236

Lu Y, Rieth S, Lohitnavy M, Dennison J, El-Masri H, Barton HA, Bruckner J, Yang RS (2008) Application of PBPK modeling in support of the derivation of toxicity reference values for $1,1,1$ trichloroethane. Regul Toxicol Pharmacol 50(2):249-260

Lunyak VV, Rosenfeld MG (2008) Epigenetic regulation of stem cell fate. Hum Mol Genet 17(R1):R28-R36

Naamane N, van Helden J, Eizirik DL (2007) In silico identification of NF-kappaB-regulated genes in pancreatic beta-cells. BMC Bioinformatics 8:55

Nicholson JK, Lindon JC (2008) Systems biology: metabonomics. Nature 23 455(7216):1054-1056

Regulation (EC) No 1907/2006 of the European parliament and of the council of 18 December 2006 concerning the registration, evaluation, authorisation and restriction of chemicals (REACH), establishing a European chemicals agency, amending directive 1999/45/EC and repealing council regulation (EEC) No 793/93 and commission regulation (EC) No 1488/94 as well as council directive 76/769/EEC and commission directives 91/155/EEC, 93/67/EEC, 93/105/EC and 2000/21/EC. Official Journal L396, $1-849,30$ December 2006. Corrigendum in Official Journal L136, 3-280, 29 May 2007

OECD (2001) OECD guideline for testing of chemicals-guideline 425: acute oral toxicity: up-and-down procedure. Organization for Economic Cooperation and Development, Paris. Adopted 21 September 1998, last updated 17 December 2001

OECD (2002) OECD guideline for testing of chemicals-guideline 429: skin sensitisation: local lymph node assay. Organization for Economic Cooperation and Development, Paris. Adopted 24 April 2002

OECD (2009a) Draft test guideline (version 7.6) on "In vitro skin irritation: reconstructed human epidermis (RhE) test method". Organization for Economic Cooperation and Development, Paris. Adopted 9 September 2009

OECD (2009b) OECD guideline for testing of chemicals-guideline 436: acute inhalation toxicity-acute toxic class (ATC) method. Organization for Economic Cooperation and Development, Paris. Adopted 8 September 2009

Pelkonen O, Kapitulnik J, Gundert-Remy U, Boobis AR, Stockis A (2008) Local kinetics and dynamics of xenobiotics. Crit Rev Toxicol 38(8):697-720

Robertson DG, Reily MD, Baker JD (2007) Metabonomics in pharmaceutical discovery and development. J Proteome Res 6(2):526-539

Ryan TP, Stevens JL, Thomas GE (2008) Strategic applications of toxicogenomics in early drug discovery. Curr Opin Pharmacol $8(5): 654-660$

Schrattenholz A, Soskić V (2008) What does systems biology mean for drug development? Curr Med Chem 15(15):1520-1528

Schug M, Heise T, Bauer A, Storm D, Blaszkewicz M, Bedawy E, Brulport M, Geppert B, Hermes M, Föllmann W, Rapp K, Maccoux L, Schormann W, Appel KE, Oberemm A, GundertRemy U, Hengstler JG (2008) Primary rat hepatocytes as in vitro system for gene expression studies: comparison of sandwich, matrigel and 2D cultures. Arch Toxicol 82(12):923-931

Sistare FD, Degeorge JJ (2008) Applications of toxicogenomics to nonclinical drug development: regulatory science considerations. Methods Mol Biol 460:239-261

Snykers S, Vanhaecke T, Papeleu P, Luttun A, Jiang Y, Vander Heyden Y, Verfaillie C, Rogiers V (2007a) Sequential exposure to cytokines reflecting embryogenesis: the key for in vitro differentiation of adult bone marrow stem cells into functional hepatocyte-like cells. Toxicol Sci 94(2):330-341

Snykers S, Vanhaecke T, De Becker A, Papeleu P, Vinken M, Van Riet I, Rogiers V (2007b) Chromatin remodelling agent trichostatin A: a key-factor in the hepatic differentiation of human mesenchymal stem cells derived of adult bone marrow. BMC Dev Biol 7:24 
Strassburg CP, Lankisch TO, Manns MP, Ehmer U (2008) Family 1 uridine- $5^{\prime}$-diphosphate glucuronosyltransferases (UGT1A): from Gilbert's syndrome to genetic organization and variability. Arch Toxicol 82(7):415-433

Sul D, Kim H, Oh E, Phark S, Cho E, Choi S, Kang HS, Kim EM, Hwang KW, Jung WW (2007) Gene expression profiling in lung tissues from rats exposed to formaldehyde. Arch Toxicol 81(8):589-597

Thum T, Borlak J (2008) Detection of early signals of hepatotoxicity by gene expression profiling studies with cultures of metabolically competent human hepatocytes. Arch Toxicol 82(2):89-101
Todd M, Garthoff B, Bernhardt W, Bodé G, Farr S, Lumley C, Pieters M, Rogiers V, Sauer U, Spielmann H, Straus J, Warngard L (1998) Issues relating to the release of proprietary information and data for use in the validation of alternative methods. The report and recommendations of ECVAM workshop 27. ATLA 26:13-20

Vangala S, Tonelli A (2007) Biomarkers, metabonomics, and drug development: can inborn errors of metabolism help in understanding drug toxicity? AAPS J 9(3):E284-E297 20

Vinken M, Papeleu P, Rogiers V, Vanhaecke T (2006) Histone deacetylase inhibitors as potent modulators of cellular contacts. Curr Drug Targets 7:773-787 